\title{
W wie Wertschätzung oder der medizinische Labelwechsel
}

\section{Dominik Heim}

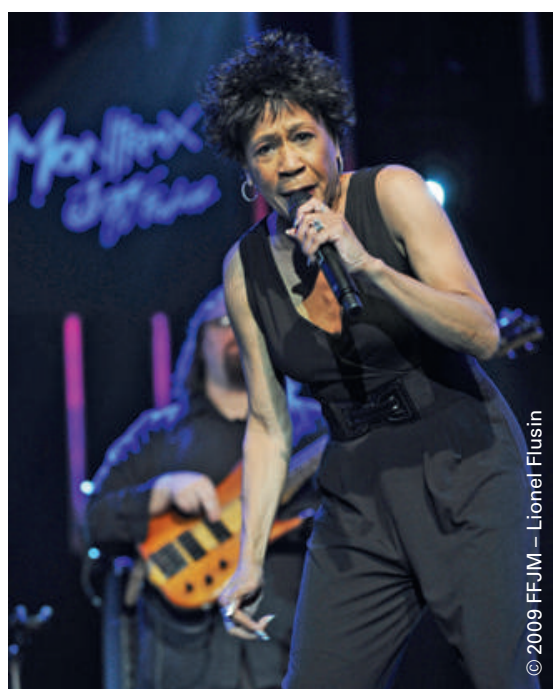

Bettye LaVette: «She's back!» tion von bekannten Rocksongs der 60er und 70er Jahre. Und die Lieder von den Beatles zu den Stones und Pink Floyd waren wieder da. Vorgetragen von einer schwarzen Soul-Sängerin! Sie ist jetzt ein Star. Sie hat die - späte - Wertschätzung, die sie lange nicht hatte!

«Wir freuen uns, Ihnen mitteilen zu können, dass wir unsere Arbeit am neuen Standort an der (Privat-)Klinik XY weiterführen.» Wir, das sind Kaderärzte, die von öffentlichen Spitälern weggehen. Und es gehen immer mehr! Vor ganz vielen Jahren sagten wir uns als junge Oberärzte an den Unikliniken, eben dann, als diese Rocksongs von den Who, von Eric Clapton und den Moody Blues gespielt wurden, dass nur jene in die Privatklinik gingen, die an den öffentlichen Spitälern nicht «unterkamen». Man aspirierte auf einen Chefarztposten, man wollte Verantwortung und Herausforderung, man wollte seine "prints» auf dem «(surgical) boulevard of fame» hinterlassen. Kritische, medizinische Zeitgenossen fragen jetzt zu Recht: Wieso dieser Exodus? Die Stelle gewechselt hat man ja im Verlaufe seiner medizinischen Ausbildung häufig. Man packte seine Harasse mit der Stereoanlage, seine Schallplatten und seine Matratze in den 2CV und zog an den Genfersee und ins Ausland. Gewechselt wurde auch im Rockgeschäft: Greg Lake wechselte 1970 von King Crimson zu Emerson, Lake and Palmer (ELP). Keith Emerson kam von den Nice und Carl Palmer von Atomic Rooster. John Mayall ersetzte seine Blues Breakers häufig: Eric Clapton ging zu den Creams, Mick Taylor zu den Rolling Stones, Peter Green zu Fleetwood Mac, und sie hatten grossen Erfolg. Solche «Königsmacher» wie Mayall gab es übrigens auch unter den damaligen Departementchefs. Es sprach für eine Klinik, seine Leute in guten Positionen platzieren zu können.

Sie haben aber auch die musikalischen Labels gewechselt: Die Beatles gründeten nach Jahren bei EMI ihr eigenes Apple Label, die Rolling Stones gingen von Decca zu Virgin Records, und John Mayall wechselte von Decca zu Polydor. Die Gründe dafür?

Die Gründe für den medizinischen Labelwechsel lässt sich in Gesprächen mit Betroffenen erahnen: Man wurde in die Kaderposition gewählt, um die chirurgischen Bedürfnisse anzugehen, um die Aussendarstellung der Klinik zu verbessern und um den chirurgischen Nachwuchs auszubilden. Aber es kam anders: Man ertrank zunehmend in administrativen Pflichten, durfte an unzähligen Strategieseminaren teilnehmen und entfernte sich immer mehr vom eigentlichen Kerngeschäft, der Patientenbehandlung. Man verweigerte sich der kommerziell begründeten Fallzahlerhöhung und überwarf sich mit der Spitalleitung. Wenn jemandem dann noch mitgeteilt wurde, dass man problemlos fünf andere Kandidaten für die Kaderposition habe, oder wenn man bei Wunsch nach einer reduzierten Spitaltätigkeit als Belegarzt erst kurz vor der Pensionierung einen Vertragsentwurf erhält, dann hat das einen Namen: mangelnde Wertschätzung.

Und so gehen viele (nicht nur wegen der besseren Work-Life-Balance) in Privatkliniken und wechseln ihr medizinisches Label. Wahrscheinlich geht die Rechnung für die öffentlichen Spitäler nicht auf. Zu Recht sprechen die Privatkliniken heute von center of excellence, denn sie haben jetzt die ärztliche excellence, und daneben verblassen Worterfindungen wie «alpines Notfallzentrum» und ähnlich sinnige Bezeichnungen in öffentlichen Spitälern. Der vielbeschworene Wettbewerb dürfte die Arroganz der öffentlichen Spitäler bestrafen.

Den erwähnten Rockgruppen ging es nach dem Labelwechsel ausgezeichnet! Und Bettye LaVette hat soeben ihr neues Album mit dem zutreffenden Titel Worthy veröffentlicht ... 